\title{
PERBANDINGAN MODEL PEMBELAJARAN LEARNING CYCLE 5E DENGAN MODEL TRADISIONAL DALAM MENIGKATKAN KOGNITIF SISWA
}

\author{
Ryzal Perdana \\ Fakultas Sains dan Teknologi Universitas Nahdlatul Ulama Lampung \\ Email:ryzalperdana2009@gmail.com
}

\begin{abstract}
This study aims to 1) Know students' initial cognitive abilities in acid-base material, 2) Know students' cognitive enhancements in acid-base material, 3) Know the effectiveness of learning 5E Learning cycle in improving students' cognitive on acid-base material. Learning Cycle $5 E$ learning model consists of 5 phases, namely Engagment phase, exploration, explaination, elaboration, and evaluation. Traditional learning models follow learning that is commonly used by teachers in everyday learning. This research is an experimental study with the number of samples in the experimental class using 30E learning cycle learning models as many as 30 students and control classes using traditional learning models of 30 students. The population in this study were all students of class XI SMA N 1 Pekalongan, Lampung. The sample in this study were students of Pekalongan 1 Public High School class XI IPA1 and XI IPA4 who had the same cognitive abilities. This study uses a quasi-experimental method with Non Equivalent (Pretest and Posttest) Control Group Design. The effectiveness of the 5E Learning Cycle learning model was measured based on the increase in students' cognitive abilities significantly. The results showed that the Learning Cycle 5E learning model was better at improving students' cognitive compared to Traditional methods. This can be seen from the average gain score of students' cognitive abilities for Traditional learning models and the 5E Learning Cycle Learning Model 0.53 and 0.65 respectively.
\end{abstract}

Keyword: Learning Cycle 5E, Tradisional dan kognitif siswa

\section{Pendahuluan}

Pendidikan merupakan suatu proses dalam mempengaruhi siswa untuk menyesuaikan diri dengan lingkungannya, sehingga diharapkan siswa dapat berfungsi dalam kehidupan masyarakat. Oleh karena itu maka siswa hendaknya memahami apa makna dari pembelaran yang mereka dapatkan, dan khususnya pembelajaran kimia yang ada di sekolah karena menurut (Depdiknas 2003) Pelajaran kimia adalah salah satu dari pelajaran dalam rumpun sains yang meru-pakan dasar bagi ilmu pengetahuan yang lain, seperti kedokteran, farmasi, dan lain-lain. Ilmu kimia dapat pula memenuhi keinginan seseorang untuk memahami berbagai peristiwa alam yang diterapkan dalam kehidupan sehari-hari, Hal ini sesuai dengan Wahab Jufri (2013: 43) "proses pembelajaran harus diarahkan pada upaya untuk mengantarkan perseta didik agar mau mengatasi setiap tantangan dalam kehidupan melalui sejumlah kompetensi yang harus dimiliki". Untuk mendapatkan kebermaknaan dalam pelajaran kimia hendaknya siswa dituntut lebih aktif dalam pembelajaran. Istilah yang biasa disebutkan adalah student centered learning. Wahab Jufri (2013: 42) "sistem penyelenggaraan pembelajaran dan penilaian hasil belajar siswa harus berubah dari pola teacher centered ke pola student centered". Guru tidaklah dipahami sebagai satu-satunya 
sumber belajar, tetapi harus mampu merencanakan dan menciptakan sumber-sumber belajar lainnya sehingga tercipta lingkungan belajar yang kondusif (Yudhi Munadi, 2010:5). Oleh karena itu guru memilih model pembelajaran yang sesuai dengan karakter dan kebutuhan siswa untuk membuat siswa lebih aktif dalam pembelajaran. Learning cycle merupakan model pembelajaran yang berorientasi pada pembelajaran konstruktivistik, yakni siswa mengkonstruk pengetahuannya sendiri dan terlibat aktif dalam berpikir pada setiap fasenya". Menurut Iskandar (2004) "learning cycle merupakan model pembelajaran sains yang efektif dan sangat dikenal oleh para pengajar sains". Pada mulanya model learning cycle diusulkan oleh Aktin dan Karplus (1962), kemudian dikembangkan sebagai modal dasar dalam Science Curriculum Improvement Study oleh Karplus dan Their (1967). Siswa umumnya mengalami peningkatan belajar ketika mereka secara aktif terlibat dalam kelas dan ketika mereka membangun pengetahuan mereka sendiri mengikuti paradigma siklus belajar (Farrell et al, 1999).

Dalam hal ini Learning Cycle $5 E$ adalah salah satu model pembelajaran yang menggunakan pendekatan konstruktivis: pengetahuan dibangun oleh peserta didik, (Bodner, 1986) dimana subjek studi disajikan sebagai suatu masalah yang harus diselesaikan oleh peserta didik menggunakan pengalamannya yang sebelumnya (Wibowo, 2010) tahapan learning cycle $5 E$ terdiri dari lima tahap (Lorsbach, 2002) tahap pembangkitan minat (engagement), eksplorasi (exploration), penjelasan (explanation), elaborasi (elaboration), dan evaluasi (evaluation). Pada tahap engagement Rodger W (2006) guru berusaha membangkitkan minat siswa dan keingintahuan. Pembangkitan bisa dilakukan dengan cara menghubungkan materi yang akan diajarkan dengan fakta yang sudah ada. Dengan jawaban siswa dengan pertanyaan yang diberikan guru maka guru dapat mengetahui seberapa besar kemampuan awal siswa (Lorsbarch, 2002) kemudian langkah selanjutnya adalah fase exploration dimana pada langkah ini (Rodger W, 2006) siswa menemukan melalui pengalaman langsung atau menyelidiki konsep. Membagi siswa dalam kelompok kecil 2-4 orang untuk bekerjasama dalam penyelidikan (Lorsbarch, 2002) kemudian pada fase ke 3 explanation "In this stage, students are introduced more formally to the lesson's science concepts" menjelaskan konsep dengan bahasa siswa sendiri yang kemudian dikembangkan ke diskusi untuk menemukan konsep baru lewat bimbingan guru (Rodger W, 2006). Kemudian fase selanjutnya elaboration siswa menghubungkan konsep baru yang didapatkan dengan konsep yang sudah ada (Lorsbarch, 2002) kemudian konsep tersebut dapat diterapkan dalam kehidupan sehari-hari (Rodger W, 2006) dan fase yang terakhir adalah evaluation pada tahap ini guru mengukur sejauh mana pemahaman siwa terhadap pembelajaran (Rodger W, 2006) dengan mengikuti langkah learning cycle $5 E$ diharapkan kemampuan kognitif siswa akan 
lebih baik dibandingkan dengan model pembelajaran tradisional. Model pembelajaran learning cycle $5 E$ lebih cepat mendorong siswa terus mendapatkan dan mempelajari konsepkonsep ilmiah sehingga siswa akan lebih bermain peran aktif dalam memperoleh pengetahuan serta membangun konsep secara lebih mandiri. Model tradisional yang digunakan di sini adalah yang biasa digunakan oleh guru di daerah Lampung, Indonesia yakni model pembelajaran teacher centered.

\section{Metode}

A non-equivalent (pretest dan posttest) control group design, a type of the quasi-experimental research, was used in the present study because participants were not randomly assigned to groups (Cresswell, 1994) Teknik pemilihan sampel yang digunakan yaitu teknik purposive sampling. Teknik purposive sampling dikenal juga sebagai sampling pertimbangan yaitu pengambilan sampel dilakukan berdasarkan pertimbangan (berdasarkan saran dari ahli). Purposive sampling akan baik hasilnya ditangan seorang ahli yang mengenal populasi (Sudjana, 2005). Dengam sample sebanyak 60 siswa SMA kelas XI IPA di Lampung, 30 siswa sebagai kelas eksperiment dengan menggunakan model pembelajaran learning cycle 5E dan 30 siswa sebagai kelas control menggunakan model pembelajaran tradisional.

Tabel.1 Desain Penelitian

\begin{tabular}{|l|c|l|l|}
\hline Kelas & Pretes & Perlakuan & Postes \\
\hline Kelas eksperimen & $\mathrm{O}_{1}$ & $\mathrm{X}$ & $\mathrm{O}_{2}$ \\
\hline Kelas control & $\mathrm{O}_{1}$ & - & $\mathrm{O}_{2}$ \\
\hline
\end{tabular}

$\mathrm{O}_{1}$ adalah Kelas eksperimen dan kelas kontrol diberi pretest, $\mathrm{O}_{2}$ adalah Kelas eksperimen dan kelas kontrol diberi posttest. $\mathrm{X}$ adalah Pembelajaran kimia dengan menggunakan pembelajaran Learning Cycle 5E. - Pembelajaran kimia menggunakan model pembelajaran tradisional. (Creswell :1994)

\subsection{Data collection tool}

Data dikumpulkan melalui instrument berupa soal pretest dan postest dengan jumah soal 10 butir dan 2 soal uraian tentang materi asam basa arrhenius untuk mengukur kemampuan kognitif siswa.

\subsection{Technique of analyzing data}

Data di anlisis secara deskriptif kuantitatif, data yang diketahui normal dan homogen maka dilanjutkan yang digunakan adalah uji parametrik yaitu uji t-test dan besarnya 
peningkatkan hasil belajar dapat dilihat pada gain score antara nilai prestest dan postes. Normalisasi gain score menurut hake (1999) dapat dihitung dengan rumus :

$$
\mathrm{N}-\operatorname{Gain}(\mathrm{g})=\frac{\text { nilai posttest-nilai pretest }}{\text { skor maksimal ideal-nilai pretest }}
$$

Sedangkan kriteria gain score dapat dilihat pada tabel 2

Tabel 2 Gain Score

\begin{tabular}{|l|l|}
\hline \multicolumn{1}{|c|}{ Gain Score Scala } & \multicolumn{1}{c|}{ Citeria } \\
\hline $\mathrm{g} \geq 0.7$ & Hight \\
\hline $0.7>\mathrm{g}>0.3$ & Medium \\
\hline $\mathrm{g}<0.3$ & Low \\
\hline
\end{tabular}

Sumber Hake (1999)

Sedangkan untuk menghitung nilai pretest dan postest yang diperoleh siswa menggunakan rumus:

$$
\text { Nilai siswa }=\frac{\text { Skor yang di peroleh siswa }}{\text { skor maksimal }} \times 100
$$

Sumber Hake (1999)

\section{Hasil dan Pembahasan.}

Berdasarkan penelitian yang telah dilakukan terhadap dua kelas yang menjadi sampel penelitian, yakni kelas XI IPA1 sebanyak 30 siswa sebagai kelas eksperimen dengan menggunakan model pembelajaran learning cycle 5E dan kelas XI IPA4 sebanyak 30 siswa sebagai kelas kontrol dengan menggunakan model pembelajaran traditional. Diperoleh hasil rata-rata nilai pretest, postes dan $\mathrm{N}$-gain tersaji dalam tabel 3.

Tabel 3. Hasil Rata-Rata Nilai

\begin{tabular}{|c|c|c|c|}
\hline Kelas & Pretest & Postest & N-Gain \\
\hline Eksperimen & 28.33 & 75.00 & 0.65 \\
\hline Kontrol & 17.67 & 61.33 & 0.53 \\
\hline
\end{tabular}

Pada tabel terlihat bahwasannya kemampuan awal siswa dalam kemampuan kognitif (pretest) dari kelas eksperimen adalah 28.33 dan pada nilai posttest sebesar 75.00 sedangkan untuk kelas kontrol kemampuan awal (pretest) sebesar 17.67 dan nilai posttest sebesar 61.33. Untuk nilai N-gain kelas eksperimen sebesar 0.63 yang lebih besar dibandingkan dengan nilai $\mathrm{N}$-Gain pada kelas kontrol sebesar 0.53 . kedua nilai $\mathrm{N}$-Gain termasuk pada kategori medium 
menurut Hake (1999). Namun nilai Gain pada kelas eksperimen lebih tinggi dibandingkan dengan kelas control, yang berarti bahwa model pembelajaran learning cycle $5 E$ lebih baik dalam meningkatkan kognitif siswa dibandingkan dengan model pembelajaran tradisional. Selanjutnya, untuk mengetahui apakah data yang diperoleh berlaku untuk keseluruhan populasi, maka dilakukan pengujian hipotesis dengan uji-t.

Sebelum melakukan uji-t, harus diketahui terlebih dahulu apakah data yang diperoleh berdistribusi normal atau tidak dan berasal dari varians yang homogen atau tidak. Uji normalitas dilakukan dengan Chi-Kuadrat. Uji normalitas pada data kognitif siswa dengan menggunakan kriteria pengujian terima Ho jika $\chi^{2}$ hitung $\leq \chi^{2}$ tabel dengan taraf $\alpha=0,05$. Berdasarkan uji normalitas yang telah dilakukan terhadap N-gain kognitif siswa pada siswa kelas kontrol dan kelas eksperimen dapat dilihat pada tabel 4 .

Tabel 4. Uji Normalitas

\begin{tabular}{|l|c|c|c|}
\hline \multicolumn{1}{|c|}{ Kelas } & $\chi_{\text {hitung }}^{2}$ & $\chi_{\text {tabel }}^{2}$ & Keterangan \\
\hline Kontrol & 0,81 & 7,81 & Normal \\
\hline Eksperimen & 0,52 & 7,81 & Normal \\
\hline
\end{tabular}

Dari tabel 4, dapat disimpulkan terima $\mathrm{H}_{0}$, artinya data kognitif siswa pada kelas kontrol dan kelas eksperimen berdistribusi normal.

Setelah dilakukan uji normalitas, selanjutnya dilakukan uji homogenitas pada data kemampuan kognitif siswa dengan menggunakan rumus $F_{\text {hitung }}=\frac{S_{1}^{2}}{S_{2}^{2}}$ dan mengambil kesimpulan dengan kriteria pengujian tolak Ho jika $\mathrm{F} \geq \mathrm{F}^{1} \frac{1}{2} \alpha\left(\mathrm{v}_{1}, \mathrm{v}_{2}\right)$ dengan taraf $\alpha=0,05$. Berdasarkan uji homogenitas yang telah dilakukan terhadap N-gain kogintif siswa diperoleh harga $F$ hitung sebesar 1,69 dan F tabel sebesar 1,85, sehingga F hitung < F tabel, dan dapat disimpulkan terima $\mathrm{H}_{0}$, artinya $\sigma_{1}=\sigma_{2}$ (data penelitian mempunyai variansi yang homogen). Dengan demikian dilakukan uji-t dengan kriteria uji terima Ho jika $t_{\text {hitung }}<t_{\text {tabel }}$ dan tolak Ho jika sebaliknya. Setelah dilakukan perhitungan diperoleh harga $t_{\text {hitung }}$ sebesar 3,24 dan harga $t_{\text {tabel }}$ sebesar 1,70 , sehingga $t_{\text {hitung }}>t_{\text {tabel, }}$, dan dapat disimpulkan tolak $\mathrm{H}_{0}$ dan terima $\mathrm{H}_{1}$. Artinya, rata-rata $\mathrm{N}$-gain kognitif siswa pada materi asam basa yang diterapkan model pembelajaran learning cycle 5E lebih tinggi dari pada rata-rata $\mathrm{N}$-gain kognitif siswa yang diterapkan model pembelajaran tradisional.

Berdasarkan hasil data penelitian tersebut menunjukkan bahwa model pembelajaran learning cycle 5E lebih efektif dibandingkan dengan model pembelajaran tradisional. Menurut Bybee \& Landes (1990) Model pembelajaran learning cycle 5E dapat digunakan untuk merancang ilmu pelajaran, dan didasarkan pada psikologi kognitif, teori pembelajaran konstruktivis, dan praktik terbaik dalam pengajaran sains. Pada tahapan sintaks learning 
cycle 5E terdiri dari lima tahap (Lorsbach, 2002) tahap pembangkitan minat (engagement), eksplorasi (exploration), penjelasan (explanation), elaborasi (elaboration), dan evaluasi (evaluation). Bybee (1997) menyatakan dengan menggunakan pendekatan ini, siswa mendefinisikan ulang, mengatur ulang, mengelaborasi, dan mengubah konsep awal mereka melalui refleksi diri dan interaksi dengan rekan-rekan mereka dan lingkungan mereka. Peserta didik mengartikan objek dan fenomena, dan menginternalisasi interpretasi tersebut dalam hal konseptual mereka saat ini. Guru sains dan pengembang kurikulum dapat berintegrasi atau menerapkan model pada beberapa tingkatan untuk mengeksplorasi keterampilan yang dimiliki peserta didik khususnya melalui model pembelajaran learning cycle 5E.

Proses pembelajaran pada tahapan sintaks pembangkitan minat (engagement) yaitu pengetahuan atau mengidentifikasi. Fase yang berpusat pada siswa harus menjadi periode motivasi yang dapat menciptakan keinginan untuk belajar lebih banyak tentang topik materi asam basa. Siswa dapat melakukan brainstorming pertanyaan pembuka atau bertanya pada diri sendiri tentang apa yang sudah siswa ketahui tentang topik ini. Hal ini menarik atau menghasilkan rasa ingin tahu siswa untuk bertukar pikiran dan merekam apa yang siswa ketahui, ingin tahu, dan tentang topik asam basa digunakan untuk menilai pengetahuan awal siswa hingga akhir dalam sepanjang durasi pelajaran.

Proses pembelajaran pada tahapan sintaks eksplorasi (exploration) yaitu fase keterlibatan yang mempromosikan fokus mental pada konsep. Fase eksplorasi menyediakan siswa dengan pengalaman belajar materi asam basa. Fase ini juga berpusat pada siswa dan aktif eksplorasi. Siswa didorong untuk menerapkan keterampilan proses, seperti mengamati, mempertanyakan, menyelidiki, menguji prediksi, berhipotesis, dan berkomunikasi, dengan teman sebaya lainnya. Fase siklus belajar ini cenderung menggabungkan yang utama aktivitas atau pengalaman berbasis inkuiri, yang mendorong siswa untuk mengembangkan keterampilan dan konsep. Peran guru adalah salah satu fasilitator atau konsultan. Selain itu, siswa didorong untuk bekerja di lingkungan belajar yang kooperatif tanpa langsung instruksi dari guru. Pada fase ini sangat unik karena siswa diberikan pengalaman secara langsung sebelum penjelasan formal apa pun tentang istilah, definisi, atau konsep didiskusikan atau dijelaskan oleh guru.

Proses pembelajaran pada tahapan sintaks penjelasan (explanation) yaitu fase "mindon" mengikuti fase eksplorasi dan lebih diarahkan oleh guru dan dibimbing oleh pengalaman siswa sebelumnya selama tahap eksplorasi. Fase penjelasan memungkinkan siswa untuk menggambarkan pemahaman mereka dan mengajukan pertanyaan tentang konsep yang telah mereka pelajari tentang materi asam basa sehingga sangat memungkinkan pertanyaan- 
pertanyaan baru akan muncul. Fase penjelasan (explanation) adalah bagian yang esensial dari pelajaran learning cycle 5E. Sebelum guru mencoba memberikan penjelasan kemudian para siswa memiliki kesempatan untuk mengekspresikan penjelasan dan gagasan mereka sendiri. Jadi, fase penjelasan merupakan waktu bagi guru sebagai fasilitator dan meminta siswa untuk menggambarkan dan mendiskusikan pengalaman belajar eksplorasi mereka. Setelah para siswa memiliki kesempatan untuk membagikan penjelasan mereka, para siswa dan guru memperkenalkan informasi ilmiah dan teknis secara langsung. Fase ini termasuk klarifikasi kesalahpahaman siswa yang mungkin muncul selama fase keterlibatan atau eksplorasi. Siswa dapat menjelaskan konsep-konsep penting dengan jelas kepada guru dan rekan-rekan mereka.

Proses pembelajaran pada tahapan sintaks elaborasi (elaboration) yaitu kegiatan dalam fase siklus pembelajaran ini harus didorong siswa untuk menerapkan pemahaman konsep baru mereka, sambil memperkuat keterampilan baru. Siswa didorong untuk memeriksa pemahaman dengan rekan-rekan mereka, atau untuk mendesain eksperimen berdasarkan keterampilan atau konsep baru yang telah mereka peroleh. Tujuan dari fase ini adalah untuk membantu mengembangkan pemahaman yang lebih dalam dan lebih luas tentang konsep materi asam basa. Siswa dapat melakukan penyelidikan tambahan, mengembangkan produk, berbagi informasi dan ide, atau menerapkan pengetahuan dan keterampilan mereka. Ini adalah peluang bagus untuk mengintegrasikan sains dengan bidang konten lainnya misalnya dalam integrasi teknologi pada materi asam basa.

Proses pembelajaran pada tahapan sintaks evaluasi (evaluation) yaitu mengukur sejauh mana pemahaman siswa terhadap pembelajaran. Proses penilaian dalam pengaturan berbasis penyelidikan (learning cycle 5E) sangat berbeda dengan di pelajaran sains tradisional. Selama pembelajaran learning cycle 5E penilaian harus dipandang sebagai proses yang berkelanjutan, dengan para guru membuat pengamatan siswa mereka saat mereka berlaku konsep dan keterampilan baru dan mencari bukti bahwa siswa telah berubah atau memodifikasi pemikiran mereka. Siswa juga dapat memiliki kesempatan untuk melakukan penilaian diri atau penilaian sejawat. Penilaian mengukur sejauh mana pemahaman siswa terhadap ketercapian tujuan pembelajaran materi asam basa dalam proses pembelajaran (Duran, 2003; Przybylski, et al; 2010).

Model pembelajaran learning cycle 5E mempunyai tahapan siklus yang efektif dalam membantu siswa memotivasi dan meningkatkan pemahaman ilmiah dan alasan, minat dalam sains, dan sikap untuk belajar sains. Tahapan learning cycle $5 \mathrm{E}$ di dasarkan pada pembelajar konstruktivis dipahami sebagai orang yang membangun mereka memiliki pengetahuan dengan menghubungkan konsep-konsep baru dengan apa yang sudah mereka ketahui. Model 
pembelajaran learning cycle 5E efektif dapat meningkatkan kemampuan kognitif siswa secara optimal (Applefield, et al., 2000; Chang, 2008; Namgyel, T and Buaraphan, K, 2017)

Model pembelajaran learning cycle 5E yang diterapkan dalam pembelajaran dikelas merupakan strategi pembelajaran yang memiliki urutan logis dan menarik dalam menyajikan materi pendidikan yaitu materi asam basa (dari mudah ke yang sulit dan dari yang sederhana ke kompleks) dengan variasi dalam metode evaluasi berkelanjutan, umpan balik yang cepat untuk mendorong siswa terus mendapatkan dan mempelajari konsep-konsep ilmiah. Interaksi antara strategi learning cycle 5E dapat mengurangi kebosanan dan membantu siswa terus belajar untuk periode yang lebih lama dan dengan demikian mempelajari lebih banyak konsep ilmiah. Pembelajaran konstruktif dan strategi learning cycle 5E yang mempunyai dua proses aktif, di mana pengetahuan ilmiah dimasukkan dalam pengetahuan siswa serta mengenai perlunya mengatur penyajian berurutan dari materi asam basa sehingga siswa akan bermain peran aktif dalam mendapatkan dan memasukkan data dalam pengetahuannya. Menyediakan lingkungan kelas aman, nyaman efisien serta efektif dalam proses pembelajaran yang memungkinkan anak-anak mendapatkan konsep ilmiah, melakukan penelitian, memecahkan masalah dan membuat keputusan (Ornek, et al; 2011; Qawasmeh \& Syouf, 2017).

\section{Kesimpulan}

Setelah dilakukan penelitian ini dapat disimpulkan bahwasannya penggunaan model pembelajaran learning cycle $5 E$ lebih baik dibandingkan dengan menggunakan model pembelajaran tradisional. Hal ini dapat dilihat dari kemampuan awal siswa dalam memahami materi asam basa kemudian dibandingkan dengan selisih antara nilai pretest dan postes kedua kelas yang menunjukan kelas eksperiment lebih baik dalam meningkatkan kemampuan kognitif siswa. Langkah pembelajaran learning cycle 5E terdiri dari, engagement, exploration, explanation, elaboration, evaluation (Lorsbach, 2002). Langkah model pembelajaran tradisional mengikuti langkah pembelajaran yang biasa digunakan oleh guru yakni dengan ceramah dan teacher centered. $5 E$ learning model has positive effect on cognitive learning stages such as interpretation, analysis and evaluation (Saka, 2006; Saygin et al. 2006; Aydoğmuş et al. 2010; Ergin et al. 2007). 5E learning cycle model enables to learn a new concept or to try to understand a concept that is known in all aspects. (Ergin et al. 2007:193).

\section{Acknowledgement}

Pada kesempatan kali ini penulis mengucapkan terimakasih kepada pihak yang sudah membantu menyelesaikan penelitian ini dan laporan ini, Dra. Nina Kadaritna, M.Si, Tasviri 
Evkar, M.Si , Septiana Agustin, M.Pd serta Guru dan Siswa SMA yang sudah bersedia membantu kelancaran penelitian ini.

\section{Referensi}

Applefield, J. M., Huber, R., \& Moallem, M. (2000). Constructivism in theory and practice: toward a better understanding. High School Journal, 84 (2), 35.

Bodner, G. (1986). Constructivism: A theory of knowledge. Journal of Chemical Education, 63, 873-878.

Bybee, R. (1997). Achieving scientific literacy: From purposes to practices. Portsmouth, NH: Heinemann Publications.

Bybee, R., \& Landes, N. M. (1990). Science for life and living: An elementary school science program from Biological Sciences Improvement Study (BSCS). The American Biology Teacher, 52 (2), 92-98.

Bybee, Rodger. W., Taylor, J.A., Gardner A., Scotter, P. V., Powell, J.C., Westbrook, A. \& Landes, N. (2006). The bscs 5e instructional model: origins and effectiveness. Office Of Science Education National Institutes Of Health. 1-80.

Chang, W. (2008). Challenges encountered in implementing constructivist teaching in physics: A qualitative approach. Asia-Pacific Forum on Science Learning and Teaching, 9(1), 1-16.

Cresswell, J.W., (1994). Research Design, Qualitative\&Quantitative Approaches. USA: Sage Publication

Duran, L. B. (2003). Investigating brine shrimp. Science Activities, 40(2), 30-34.

Depdiknas.(2003). Undang-undang sistem pendidikan nasional. Department pendidikan nasional. Indonesia

Ergin, İ., Kanlı, U.\& Tan, M. (2007). Fizik eğitiminde 5e modeli'nin öğrencilerin akademik başarısına etkisinin incelenmesi. Gazi Eğitim Fakültesi Dergisi, 27(2), 191-209.

Gökhan Demircioğlu, Gülşen Çağatay. (2013). The effect of laboratory activities based on 5e model of constructivist approach on 9th grade students' understanding of solution chemistry . Procedia Social and Behavioral Sciences 116 (2014) 3120 - 3124

Jufri, Wahab. (2013). Belajar dan Pembelajaran Sains. Bandung: Pustaka Reka Cipta.

Lorsbach. (2002). The Learning Cycle as a Tool for Planning Science Instruction www.coe.ilstu.edu/, Ilinois State University. USA

Namgyel, T and Buaraphan, K. (2017) The development of simulation and game in 5E learning cycle to teach photoelectric effect for grade 12 students, Journal Asia-Pacific Forum on Science Learning and Teaching, 18( 1), 1-30

Ornek, F., \& Zziwa, B. J. (2011). Measuring "g" by using trajectory projectile motion: 5E learning cycle and low-cost materials. Journal Asia-Pacific Forum on Science Learning and Teaching, 12(1), 1-7. 
Przybylski, A. K., Rigby, C. S., \& Ryan, R. M. (2010). A motivational model of video game engagement. Review of General Psychology, 14(2), 154-166

Qawasmeh, M. R., and Syouf A..A.Al ( 2017). The Effect of Using Computerized 5E's Learning Cycle Model on Acquiring Scientific Concepts among Fourth Graders. American Journal of Educational Research, 5 (5), 579-587

Saka, A. (2006). Fen bilgisi öğretmen adaylarının genetik konusundaki kavram yanılgılarının giderilmesinde5e modelinin etkisi. Yayımlanmamış Doktora Tezi. Karadeniz Teknik Üniversitesi Fen Bilimleri Enstitüsü, Trabzon.

Sudjana. (2005). Metoda Statistika. Tarsito. Bandung.

Wibowo, Arie. (2010). Penerapan Model Pembelajaran Siklus Belajar (Learning Cycle) 5E dalam Meningkatkan Hasil Belajar Siswa Pada Mata pelajaran Teknologi Informasi dan Komunikasi (Penelitian Kuasi Eksperimen Terhadap Siswa Kelas VII SMPN 1 Lembang Tahun Ajaran 2009/2010)

Yudhi Munadi. (2010). Media Pembelajaran. Jakarta: Gaung Persada (GP) Press. 